\title{
Treatment Strategy for the Patient with Hippocampal Sclerosis Who Failed to the First Antiepileptic Drug
}

\section{Review}

Journal of Epilepsy Research pISSN 2233-6249 / eISSN 2233-6257

Received April 29, 2014

Accepted May 15, 2014

Corresponding author: Sang Kun Lee

Department of Neurology, Seoul National

University Hospital, 101 Daehak-ro,

Jongno-gu, Seoul 110-744, Korea

Tel. $+82-2-2072-2923$

Fax. +82-2-36727553

E-mail; sangkun2923@gmail.com

\author{
Sang Kun Lee \\ Department of Neurology, Seoul National University College of Medicine, Seoul, Korea
}

Despite many epilepsy patients respond to antiepileptic drugs (AED) successfully, more than $30 \%$ of patients continue to have seizures on multiple AEDs. The refractory epilepsy increases the risk of cognitive deterioration, psychosocial dysfunction, and sudden unexpected death of epilepsy patients (SUDEP). It is important to identify refractory epilepsy early and make the goal of epilepsy treatment as the prevention of decline in social, vocational, and cognitive performances and minimizing the risk of accident or SUDEP. The syndrome of medial temporal lobe epilepsy with hippocampal sclerosis (MTLE with $\mathrm{HS}$ ) is often resistant to AEDs, and surgically remediable. Initially well-controlled seizures often become intractable to AEDs. There are progressive behavioral changes including increasing memory deficit. Surgical outcome is also worse with longer duration of epilepsy or increasing age at surgery, which suggests that MTLE is a progressive disorder. Some emphasized the ultimate intractability of MTLE in which intractability of MTLE could be evident only after some years following initial diagnosis. However, when patients considered to have intractable epilepsy were followed up for a long period of time, many of them experienced seizure-free state. Some studies clearly demonstrated the wax and wane courses of treatment response in epilepsy. Late remission could be achieved up to in a half of patients. Thus intractable state is not a static condition but a fluctuating one and initial refractoriness does not necessarily mean the final intractability. Even though the chance of seizure remission with AEDs is not high for MTLE, some of them do well respond to drugs. It is even possible to withdraw AEDs for a few patients. Though epilepsy surgery is very effective method to treat MTLE, considering the fluctuation courses of intractability and the possibility of delayed remission, at least two adequate AEDs could be applied to the patients before surgery. However, medical intractability becomes evident by definition, it is not reasonable to delay epilepsy surgery. (2014;4:1-6)

Key words: Treatment, Refractory epilepsy, Hippocampal slclerosis

\section{Introduction}

Despite many epilepsy patients do respond well to antiepileptic drugs (AEDs), more than $30 \%$ of patients continue to have seizures on multiple AEDs. A study based on 525 unselected and untreated adolescents and adult patients showed that $63 \%$ of patients became seizure-free for a 5 year median follow-up. ${ }^{1}$ The symptomatic or cryptogenic epilepsy was more likely to continue to report seizures and partial epilepsy rather than generalized epilepsy is less likely to be controlled.

However, the definition of medical intractability has not yet been clearly defined. There are many factors in considering the definition of medical refractoriness. They are seizure frequency, a number of
AED failures, duration of unresponsiveness, etc. No single definition can satisfy the whole areas. For example, the duration and a number of AED trials should be defined on the baseline seizure frequency. Furthermore, repeated remissions and relapses could occur during the long-term follow period. A study based on pediatric patients demonstrated that after a median 10 year follow-up from a second drug failure, 37\% were seizure-free for at least one year and 23\% became seizure-free for at least 3 years. ${ }^{2}$ Most authors suggested a period of at least more than 6 to 24 month of seizure-free period as medically tractable epilepsy (Table 1).-10

Another important issue is a number of AED failures. Around 60\% of patients were successfully treated with the first or second AED. ${ }^{1,11}$ The response to the first AED was the most powerful predictor for the 
long-term prognosis. Initially they found that among the patients in whom the first AES was unsuccessful, only $32 \%$ became seizure-free and only $3 \%$ was controlled by two AEDs in combination. Including further follow-up period, they demonstrated that $68 \%$ of 1098 patients became seizure-free, in which the chance of seizure freedom declined with the number of AED regimens; seizure freedom rates were $49.5 \%, 36.7 \%, 24.4 \%$, and $16.2 \%$ on the first, second, third and fourth trial of AEDs respectively either in monotherapy or in combiantion. ${ }^{11}$ They also found out that seizure freedom patterns could be variable; early and sustained seizure freedom (37\%), delayed but sustained seizure freedom (22\%), fluctuation between periods of seizure freedom and relapse (16\%), and no seizure freedom $(25 \%)$. The fact that the probability of seizure freedom in newly diagnosed epilepsy rapidly declined according to the subsequent trial number of AEDs was confirmed by another study. ${ }^{12}$ Seizure freedom rate was decreasing to the order of trial of AEDs; only $16.6 \%$ became seizure-free after failure of two to five AEDs.

Until now there is no consensus on a number of AED failures to make criteria of medically intractable epilepsy. Usually at least two or more AEDs should be tried before going into consideration of epilepsy surgery. International League Against Epilepsy (ILAE) proposed definition of intractability on $2010 .{ }^{13}$ Level one is a general scheme to categorize outcomes of each treatment modalities; seizure freedom or treatment failure. Level two defines the drug resistant epilepsy; failure of adequate trials of two tolerated and appropriately chosen AEDs to achieve sustained seizure freedom.

There are important reasons to define medical intractability. It is imperative to do various studies and compare the results. Early detection of medically refractory epilepsy can make us consider other interventions such epilepsy surgery. Furthermore, the refractory epilepsy increases the risk of cognitive deterioration, psychosocial dysfunction, and sudden unexpected death of epilepsy patients (SUDEP). It is important to make the goal of epilepsy treatment as the prevention of decline in social, vocational, and cognitive performances and minimizing the risk of accident or SUDEP. In this sense, a large portion of treatment resources have been utilized to treat the refractory epilepsy. There are also a portion of patients who have progressive nature of disease. In a broader sense, medial temporal lobe epilepsy with hippocampal sclerosis (MTLE with HS) is one of these categories.

Table 1. Definitions of seizure remission by different authors

\begin{tabular}{|c|c|c|}
\hline Author & Definition & Remarks \\
\hline Arts (1999) & $\begin{array}{l}\text { Seizure remission of } \\
<6 \text { months at } 2 \text { years }\end{array}$ & $\begin{array}{l}\text { Prospective study } \\
30 \% \text { of the cohort : poor outcome }\end{array}$ \\
\hline Casetta (1999) & $\begin{array}{l}>=1 \text { seizure/month } \\
\text { and } 3 \text { failed drugs }\end{array}$ & $\begin{array}{l}\text { Community based case-controlled study } \\
\text { Early predictors of intractability: } \\
\text { Onset }<1 \text { year of age } \\
\text { Symptomatic etiology } \\
\text { High seizure frequency before treatment }\end{array}$ \\
\hline Camfield (2005) & $>=1$ seizure $/ 3$ months and 3 failed drugs & \\
\hline Dlugos (2001) & Persistent seizure between $18-24$ Mo with 2 drugs & $\begin{array}{l}\text { Predictors for refractory TLE: } \\
\text { Early risk factor } \\
\text { Abnormal MRI } \\
\text { Failure of } 1 \text { st AED }\end{array}$ \\
\hline Spooner (2006) & failure of $>=2$ drugs & Predictor of intractability for children with TLE: Lesions on MRI \\
\hline Berg (2001) & $\begin{array}{l}\text { failure of }>=2 \text { drugs } \\
>=1 \text { seizure/Mo. } \\
<3 \text { Mo seizure free }\end{array}$ & $\begin{array}{l}\text { Refractory epilepsy: } 10 \% \\
\text { Risk factors: } \\
\text { Symptomatic generalized epilepsy } \\
\text { High initial seizure frequency }\end{array}$ \\
\hline Berg (2006) & $\begin{array}{l}1 \text { seizure/Mo for } 18 \text { Mo with } 2 \text { drugs } \\
\text { Two drug failure }\end{array}$ & $\begin{array}{l}\text { Percentage of refractory epilepsy according to different definitions: } \\
14 \% \\
23.2 \%\end{array}$ \\
\hline Picot (2008) & $\begin{array}{l}1 \text { seizure/Mo. For } 18 \text { Mo with } 2 \text { drugs } \\
1 \text { seizure/year with } 2 \text { drugs }\end{array}$ & $\begin{array}{l}\text { Geographical prevalence of refractory epilepsy } \\
0.9 / 1,000(15.3 \% \text { of epilepsy) } \\
1.4 / 1,000(22.1 \% \text { of epilepsy) }\end{array}$ \\
\hline
\end{tabular}

Mo, months; > = 1 seizure/3 months, one or more seizures per 3 months; > = 2 drugs, two or more antiepileptic drugs; < 3 Mo seizure free, less than 3 month seizure-free period, AED: antiepileptic drugs. 


\section{MTLE with HS}

The syndrome of MTLE with HS is often resistant to AEDs, and surgically remediable. ${ }^{14}$ There are unique and homogenous clinical features including history, semiology, histology, MRI, PET, and EEG. The natural history is also characteristic. High incidence of initial precipitating injury (IPI) precedes the development of epilepsy in MTLE. IPI includes febrile seizure, trauma, hypoxic event, and intracranial infection. There is a usually latent period between IPI and appearance of habitual seizures. Seizures may be initially easily controlled for some time. However, initially well-controlled seizures often become intractable to AEDs. There are progressive behavioral changes including increasing memory deficit. Progressive memory impairment was notable in patients whose seizures were intractable, which suggested frequent seizures contributed this memory loss. ${ }^{15}$ Contralateral spikes on interictal EEG can appear along with the duration of epilepsy. Surgical outcome is also worse with longer duration of epilepsy or increasing age at surgery, ${ }^{16-19}$ which suggests that MTLE is a progressive disorder. Age at surgery as well as duration of epilepsy has affected surgical outcome, which may mean the presence of the inherent progressive nature of MTLE. MTLE resulting from early damage followed by anatomical and functional reorganization may be progressive even before the development of the first seizur. ${ }^{16}$ Secondarily generalized tonic clonic seizure (2GTCS) also affected the surgical outcome including relapse after surgery. ${ }^{16,20}$ Repeated 2GTCS can enhance epileptogenic properties. As a result, early surgery for intractable MTLE may be better with a doseresponse effect. ${ }^{16}$

Some MRI and pathological studies back up the progressive nature of the disease. Longitudinal and cross sectional studies of MRI supported this progression, which demonstrated the progressive atrophy of bilateral hippocampi and neocortex compared with age matched controls. ${ }^{21}$ A statistically significant correlation was found between the duration of epilepsy and the number of epileptogenic structures. ${ }^{22}$

\section{Onset and stability of intractable epilepsy}

If MTLE is a progressive disorder and becomes intractable to AEDs in almost all cases, it is unreasonable to treat it medically and delay epilepsy surgery. Epilepsy surgery for MTLE is very effective. In one randomized trial of temporal lobectomy, 40 patients were randomized to delayed surgery. ${ }^{23}$ Only one patient was seizure free for the entire period after randomization. One study also compared the surgical treatment and the medical treatment for 101 patients failed to achieve seizure control with at least two AED trials. ${ }^{24}$ Only $12 \%$ of 75 patients with medical treatment could achieve seizure remission while $73 \%$ of 26 patients with surgery became seizure-free state. Although the effectiveness of surgery is evident, it should be noted that when these patients were recruited, they were already in a refractory state. In other words, patients with medically tractable MTLE with HS were not included in these studies.

Other important facts should also be considered in the interpretation of refractoriness. First of all, the onset of intractability is a controversial issue. One implicit dogma of intractability is that intractable epilepsy is intractable from the start. Epileptic encephalopathy is a classic example suitable for this. Glasgow observational study ${ }^{25}$ demonstrated that $87 \%$ of intractable epilepsy patients were de novo intractable while only $13 \%$ of them were initial responders. However, not all intractable epilepsies fit this assumption. Whether initially well-controlled MTLE becomes inevitably intractable over the period of time or some of them have a long period of medical remission with stability is not clear. Twenty-two percent of 67 patients with MTLE evaluated for epilepsy surgery had a previous period of at least 1 year seizure remission (average, 5.9 years), which emphasized the ultimate intractability of MTLE. ${ }^{26}$ One prospective study confirmed that intractability could be evident only after some years following initial diagnosis. ${ }^{27}$ Another large multicenter study of resective epilepsy surgery also demonstrated the median 20 year gap between the age at surgery and the age at onset of epilepsy in which a quarter of patients had a seizure free period for more than a year. Especially almost a half of the patients whose epilepsy onset was before 5 years of age reported at least more than one year remission. ${ }^{27}$

Aside from the fact that medical intractability could be observed some years after initial diagnosis, these findings emphasized the instability of treatment response during the course of disease. Some of initially refractory patients could reach the long-term or terminal remission. In a retrospective study, a series of children considered to have intractable epilepsy were followed up for up to 20 years. Many of them experienced seizure-free state. Another long-term follow-up study of children clearly demonstrated the wax and wane courses of epilepsy. ${ }^{28}$ Late remission was achieved in $50 \%$. $19 \%$ of the patients who had remission and relapsing courses finally reached terminal remission. De novo intractability was found only in $19 \%$. Thus intractable state is not a static condition but a fluctuating one and initial refractoriness does not necessarily mean the final intractability. 


\section{Treatment strategy for MTLE with HS failed Illustrative cases 1 on the first AED}

MTLE with HS is a good candidate for epilepsy surgery and delayed surgery may contribute the poor surgical outcome. Anterior temporal lobectomy performed for the treatment of intractable MTLE yielded worthwhile improvement (75-95\%), including complete remission of seizure (68-85\%) in many patients. ${ }^{16,29-31}$ Although 15\% may have long-term relapse, ${ }^{32}$ cure which was defined to seizure free without AED could be achieved in 34.5-47.2\%. ${ }^{33-35}$ However, even though the chance of seizure remission with AEDs is not high for this syndrome, some of them do well respond to drugs. It is even possible to withdraw AEDs for a few patients. 84 patients with TLE who achieved seizure remission for at least two years were followed up for more than two years after discontinuation of AED. ${ }^{36} 39$ of 84 patients had HS. Although seizure recurrence was commoner in the patients with HS, AEDs were successfully withdrawn in 10 of 39 patients with HS. Because too much delayed surgery may lead to negative effect on surgical outcome, it is important to identify prognostic factors of medical treatment (Fig. 1). So far there is no clear prognostic factors identified which are specific for MTLE with HS. One study using voxel based morphometry tried to differentiate drug responsive patients with TLE from drug refractory ones. ${ }^{37}$

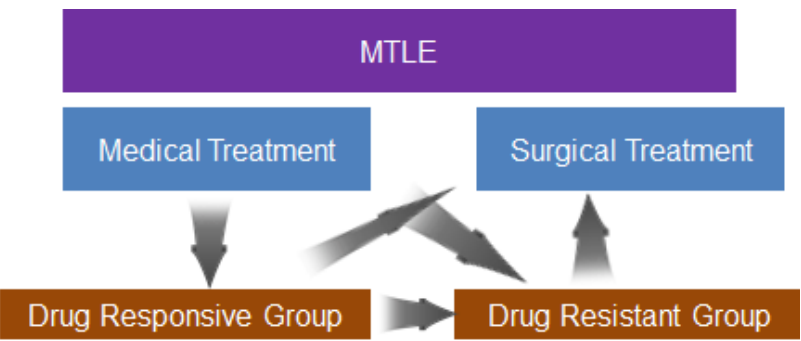

Figure 1. Interchanging and fluctuating courses between remission and refractoriness in the treatment of medial temporal lobe epilepsy.

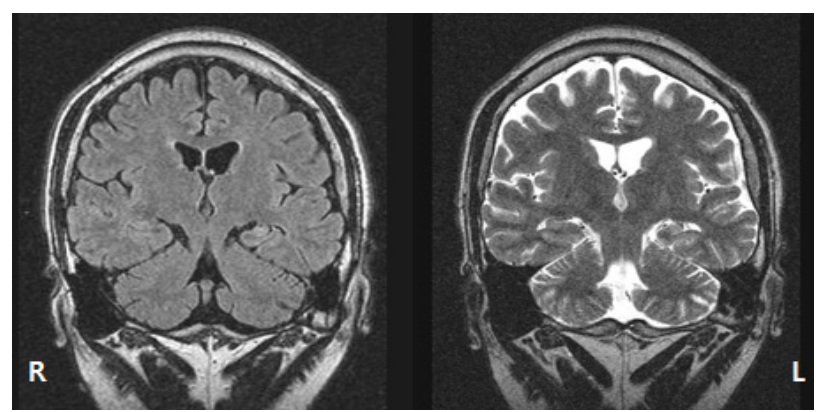

Figure 2. FLAIR MRI (left) and T2-weighted MRI clearly showed the left hippocampal sclerosis.
Thirty seven-year-old male patient had experienced seizure since 3-year-old-age. His seizures was characterized by strange feeling as aura followed by brief loss of consciousness with staring and oroalimentary automatism, which occasionally progressed to secondarily generalized tonic-clonic seizures (2GTCS). The average frequency of seizures was three times a month for complex partial seizures and one or two times a month for 2GTCS. Combination of four different antiepileptic drugs did not decrease the seizure frequency effectively.

Video- EEG monitoring showed brief automotor seizure followed by version to the right side and 2GTCS. Frequent independent interictal sharp waves were found in the bilateral temporal areas. Ictal EEG showed the left temporal dominant rhythmic theta activity at seizure onset. Epilepsy protocol MRI showed the left hippocampal sclerosis (Fig. 2). FDG-PET scan showed the left temporal hypomeatoblism.

We performed the standard anterior temporal lobectomy for the left side. The patient became seizure free since then for three years with AED monotherapy.

\section{Illustrative cases 2}

Thirty nine-year-old male patient had experienced seizure since 24-year-old-age. He had experienced GTCS during sleep. His seizures had been well controlled by phenobarbital at the local clinic for the initial 2 years. However, the family members noticed brief staring with lip smacking during sleep. The average frequency of this phenomenon was two times a week. The doctor at the local clinic switched phenobarbital to vigabatrin. The intensity of seizures was slightly decreased but the frequency did not change.

Video-EEG monitoring showed brief unresponsiveness with oroalimentary and hand automatisms followed by postictal confusion. Ictal EEG demonstrated $5 \mathrm{~Hz}$ rhythmic theta activity on the right temporal area. Epilepsy protocol MRI showed the right hippocampal sclerosis (Fig. 3). FDG-PET scan showed the right temporal hypomeatoblism.

We added lamotigine and increased dose up to $350 \mathrm{mg}$ per day. He has been seizure free for 11 years since then by this combination.

\section{Conclusions}

MTLE is a progressive disorder and a good candidate for epilepsy 


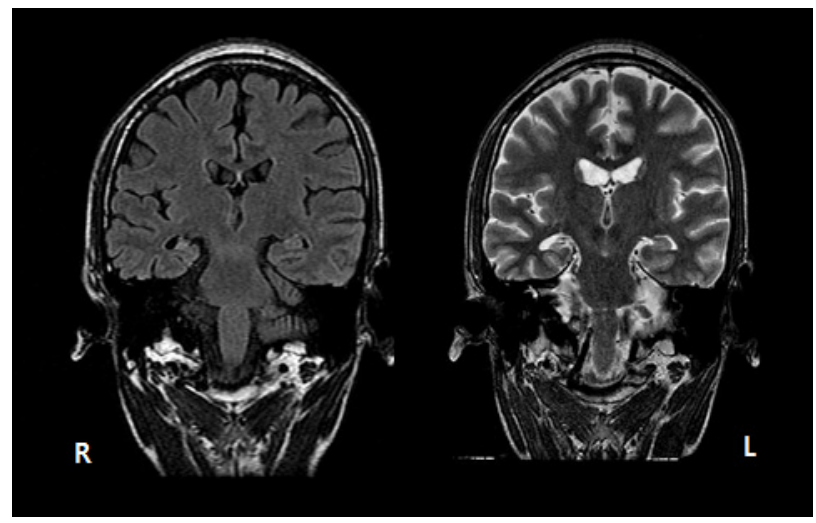

Figure 3. FLAIR MRI (left) and T2-weighted MRI showed the definite right hippocampal sclerosis.

surgery. Although epilepsy surgery is very effective method to treat MTLE, at least two adequate AEDs could be applied to the patients before surgery. Intractability can follow wax and wane courses. However, medical intractability becomes evident by definition, it is not reasonable to delay epilepsy surgery. Too delayed surgery may contribute the poor surgical outcome and progressive decline of cognition can be brought about. Age of patients and willingness to surgery are also important in deciding surgery for TLE.

\section{References}

1. Kwan P, Brodie MJ. Early identification pf refractory epilepsy. N Eng J Med 2000;342:314-19.

2. Berg AT, Levy SR, Testa FM, D'Souza R. Remission of epilepsy after two drug failures in children: a prospective study. Ann Neuro/ 2009;65: 510-9.

3. Arts WF, Geerts AT, Brouwer OF, et al. The early prognosis of epilepsy in childhood: the prediction of a poor outcome. The Dutch study of epilepsy in childhood. Epilepsia 1999;40:726-34.

4. Casetta I, Granieri E, Monetti VC, et al. Early predictors of intractability in childhood epilepsy: a community based case control study in Copparo, Italy. Acta Neurol Scand 1999;99:329-33.

5. Camfield $P$, Camfield $C$. The frequency of intractable seizures after stopping AEDs in seizure-free children with epilepsy. Neurology 2005; 64:973-5.

6. Dlugos DJ, Sammel MD, Strom BL, Frrar JT. Response to first drug trial predicts outcome in childhood temporal lobe epilepsy. Neurology 2001;57:2259-64.

7. Spooner CG, Berkovic SF, Mitchell LA, Wrennall JA, Harvey AS. Newonset temporal lobe epilepsy in children: lesion on MRI predicts poor seizure outcome. Neurology 2006;67:2147-53.

8. Berg AT, Shinnar S, Levy SR, et al. Defining early seizure outcomes in pediatric epilepsy: the good, the bad, and the in-between. Epilepsy Res 2001;43:75-84.

9. Berg AT, Vickrey BG, Testa FM, et al. How long does it take for epilepsy to become intractable? A prospective investigation. Ann Neurol 2006;60:73-9.

10. Picot MC, Baldy-Moulinier M, Daures JP, Dujols P, Crespel A. The prevalence of epilepsy and pharmacoresistant epilepsy in adults: a population-based study in a Western European country. Epilepsia 2008:49:1230-8.

11. Brodie MJ, Barry SJ, Bamagous GA, Norrie JD, Kwan P. Patterns of treatment response in newly diagnosed epilepsy. Neurology 2012;78: 1548-54.

12. Sciller $Y$, Najjar $Y$. Quantifying the response to antiepileptic drugs: effect of past treatment history. Neurology 2008;70:54-65.

13. Kwan P, Arziamanoglou A, Berg AT, et al. Definition of drug resistant epilepsy: consensus proposal by the ad hoc Task Force of the ILAE Commission on Therapeutic Strategies. Epilepsia 2010;51:1069-77.

14. Özkara Ç, Aronica E. Hippocampa sclerosis. In: Stefan H, Theodore WH, eds. Handbook of Clinical Neurology. Vol. 108 Epilepsy: Part II. Elsevier, Amsterdam, Netherlands 2012:621-39.

15. Hanoglu L, Ozaka C, Keskinklic C, et al. Correlation between 1H MRS and memory before and after surgery in mesial temporal lobe epilepsy with hippocampal sclerosis. Epilepsia 2004;45:632-640.

16. Jeong SW, Lee SK, Hong KS, et al. Prognostic factors for the surgery for mesial temporal lobe epilepsy: longitudinal analysis. Epilepsia 2005:46:1273-9.

17. Jeong SW, Lee SK, Kim KK, et al. Prognostic factors in anterior temporal lobe resections for mesial temporal lobe epilepsy: multivariate analysis. Epilepsia 1999;40:1735-59.

18. Janszky J, Janszky I, Scuulz R, et al. Temporal lobe epilepsy with hippocampal sclerosis: predictors for long-term surgical outcome. Brain 2005; 128:395-404.

19. Armon C, Radtke RA, Friedman AH, et al. Predictors of outcome of epilepsy surgery; multivariate analysis with validation. Epilepsia 1996; 37:814-21.

20. Mclntosh AM, Kalnins RM, Mitchell LA, et al. Temporal lobectomy: long-term seizure outcome, late recurrence and risk for seizure recurrence. Brain 2004;127:2018-30.

21. Bernhardt BC, Worsley KJ, Kim H, et al. Longitudinal and cross-sectional analysis of atrophy in pharmacoresistant temporal lobe epilepsy. Neurology 2009;72:1747-54.

22. Bartolomei F, Chauvel P, Wendling F. Epileptogenicity of brain structures in human temporal lobe epilepsy: a quantified study from intracerebral eeg. Brain 2008;131:1818-30.

23. Wiebe $S$, Blume $W T$, Girvin JP, et al. A randomized, controlled trial of surgery for temporal-lobe epilepsy. N Eng J Med 2001;345:311-8.

24. Yasuda $\mathrm{CL}$, Tedeschi $\mathrm{H}$, Oliveira ELP, et al. Comparison of short-term outcome between surgical and clinical treatment in temporal lobe epilepsy: a prospective study. Seizure 2006;15:35-40. 
25. Mohanraj R, Brodie MJ, Outcomes in newly diagnosed localizationrelated epilepsies. Seizure 2005;14:318-23.

26. French JA, Williamson PD, Thadani VM, et al. Characteristics of medial temporal lobe epilepsy: Results of history and physical examination. Ann Neurol 1993;34:774-80.

27. Berg AT, Vickrey BG, Langfitt JT, et al. The multicenter study of epilepsy surgery: recruitment and selection for surgery. Epilepsia 2003; 44:1425-1433.

28. Sillanpää, Schmidt D. Natural history of treated childhood-onset epilepsy: prospective, long-term population-based study. Brain 2006;129: 617-24.

29. Engel J Jr. Current concepts: surgery for seizure. N Engl J Med 1996; 334:647-52.

30. Lüders HO, Awad I. Conceptual considerations. In: Lüders HO, ed. Epilepsy surgery. New York: Raven Press, 1991:51-62.

31. Rasmussen T. Surgical treatment of complex partial seizures: results, lessons, and problems. Epilepsia 1983;24(Suppl1):65-76.
32. Spencer SS, Berg AT, Vickrey BG, et al. Predicting long-term seizure outcome after respective epilepsy surgery: the multicenter study. Neurology 2005;912-8.

33. Wieser $H G$, Hane A. Antiepileptic drug treatment before and after selective amygdalohippocampectomy. Epilepsy Res 2003;55:211-23.

34. Ozakara C, Uzan M, Benbir G, et al. Surgical outcome of patients with mesial temporal lobe epilepsy related to hippocampal sclerosis. Epilepsia 2008;49:696-9.

35. Lee SY, Lee JY, Kim DW, Lee SK, Chung CK. Factors related to successful antiepileptic drug withdrawal after anterior temporal lobectomy for medial temporal lobe epilepsy. Seizure 2008;17:11-8.

36. Cardoso TA, Coan AC, Kobayashi E, Guerreiro CA, Li LM, Cendes F. Hippocampal abnormalities and seizure recurrence after antiepileptic drug withdrawal. Neurology 2006;67:134-6.

37. Bilevicius E, Yasuda CL, Silva CA, Lopes-Cendes I, Cendes F. Antiepileptic drug response in temporal lobe epilepsy: a clinical and MRI morphometric study. Neurology 2010;75:1695-1701. 